the stimulus intensity where necessary to compensate for effects of medication.

A third way in which supervision of ECT sessions may be beneficial is in helping to make decisions about restimulating patients when doubtful seizures have been achieved, and adjusting dosage settings at subsequent treatments. It is not easy to do this effectively without being present at the majority of sessions, and observing the response of patients to treatment.

The doctor who supervises ECT also has a more general role in educating medical and other groups of staff about correct use of ECT, and drawing up protocols for use in the ECT clinic. The Royal College of Psychiatrists (1995) recommend that dedicated time be provided to perform these duties.

I do not doubt the superiority of newer ECT machines such as the Thymatron DGx in allowing ECT to be more flexibly tailored to individual needs, in treating patients with higher convulsive thresholds and in allowing closer monitoring of treatment. This study shows, however, that it is possible to improve the delivery of ECT substantially by carefully supervising and monitoring the use of existing equipment.

\section{Acknowledgements}

I thank Dr Agnès Nalpas, Patrick Dwyer and the other members of the ECT team whose commit- ment and enthusiasm enabled this work to take place.

\section{References}

FEIGHNER, J. P. \& BOYER, W. F. (1991) Selective Serotonin Reuptake Inhibitors: The Clinical Use of Citalopram. Fluoxetine, Fluvaxamine, Paraxetine and Sertraline. Chichester: John Wiley.

MARKOWITZ, J. C. \& BROWN, R. P. (1987) Seizures with neuroleptics and antidepressants. General Hospital Psychiatry, 9, 135-141.

Pettinati, H. M., STEPhenS, S. M., Willis, K. M., et al (1996) Evidence for less improvement in depression in patients taking benzodiazepines during unilateral ECT. American Journal of Psychiatry, 147, 1029-1035.

ROYAL COLLEGE OF PSYCHIATRISTS (1995) The ECT Handbook (Council Report CR39). London: Royal College of Psychiatrists.

STRÓMGREN, L., DAHL, J., FJELDBEg, N., et al (1980) Factors influencing seizure duration and number of seizures applied in unilateral electroconvulsive therapy. Acta Psychiatrica Scandinavica, 62, 158-165.

TREZISE. K. \& CONLON. B. (1997) Effects of changes in practice of electroconvulsive therapy over a two year period. Psychiatric Bulletin, 21, 10-12.

Kate Trezise, Specialist Registrar in Learning Disability Psychiatry, Ridge Hill Hospital, Brierley Hill Road, Wordsley, Stourbridge, West Midlands

\title{
Proposed change in service delivery and stress among nursing staff
}

\author{
Ajit Shah and Tamal De
}

Aims and method The impact of major organisational change in a psychogeriatric service was examined in a naturalistic and opportunistic study, which was prospectively conducted.

Results A positive association between the organisational change of the proposed closure and relocation of a psychogeriatric ward and stress among the nursing staff as measured by the General Health Questionnaire was demonstrated.

Clinical implications Policy-makers, purchasers and providers need to consider the implication of such stress and develop strategies to minimise stress prior to any major policy change.
The provision of health services is constantly evolving to incorporate legislative changes, economic factors and scientific developments. Several recent legislative changes in the National Health Service (NHS), including the NHS and Community Care Act 1990, have resulted in major changes in health service provision. The impact of such changes on NHS staff has been poorly examined. Nursing staff left behind in large psychiatric hospitals during deinstitution-alisation experience burn-out, poor morale and stress (Lamb, 1977; Mendal, 1979). The closure of a continuing care psychogeriatric ward, initiated by the local NHS 
purchasers, offered a natural experiment to examine the effect of impending organisational change on stress among the nursing staff during the course of another study.

\section{The study}

\section{Location}

This study was performed in a 24-bed psychogeriatric continuing care ward at a London district general hospital serving a catchment area of 23000 elderly. The whole psychogeriatric service included a 16-bed acute admission ward, 10-bed respite ward and two multi-disciplinary community teams.

\section{Measurement of stress}

The original study evaluated the efficacy of an educational package in reducing aggressive behaviour among the patients and stress among the nursing staff. Aggressive behaviour was continuously measured over an 18-week period. The educational package, directed at the nursing staff, was implemented during weeks 7 to 12 (inclusive). Stress among the nursing staff was measured using the 30-item General Health Questionnaire (GHQ-30; Goldberg, 1978) at weeks $1,7,13$ and 19 . Using the conventional GHQ scoring method, a GHQ-30 score of five or more indicates a case of psychiatric morbidity (Goldberg \& Williams, 1988). Brodaty \& Andrews (1983) demonstrated the transience of disorders measured by GHQ-30 when serially administered every two months to general practice attenders. However, in such situations longstanding disorders may be missed as respondents will score zero for chronic symptoms as the answer will be 'same as usual'. A modified scoring system called Chronicity and the General Health Questionnaire (CGHQ) has been developed to overcome this difficulty (Goodchild \& Duncan-Jones, 1985) and the scores are said to be normally distributed. The nursing staff were first informed of the purchasers plans to close this ward and transfer patients to a private nursing home just before completion of the week $13 \mathrm{GHQ}-30$. Further details of the purchasers plans emerged in the period between weeks 12 and 18. All agency nurses and one regular nurse on long-term sickness absence were excluded.

\section{Findings}

The demographic characteristics of the 15 regular nurses studied are given in Table 1. GHQ-30 scores for all 15 nurses were available for weeks 1,7 and 13. However, by week 19, two nurses had left the ward to work elsewhere; thus, only $13 \mathrm{GHQ}-30$ s were available for week 19. The predominant thrust of the proposed changes occurred between weeks 12 and 19. Thus, weeks
Table 1. Characteristics of the nursing staff

\begin{tabular}{ll}
\hline & $\begin{array}{l}\text { Number } \\
(n=15)\end{array}$ \\
\hline $\begin{array}{l}\text { Gender } \\
\text { Male }\end{array}$ & 2 \\
Female & 13 \\
Grade & 10 \\
A & 3 \\
E & 1 \\
F & 1 \\
Median age (range) & $44(26-59)$ years \\
Median duration in nursing & $10(2.5-32)$ years \\
Median duration in & $7.25(2.5-25)$ years \\
psychiatric nursing & \\
Median duration on the ward & $54(9-120)$ months \\
\hline
\end{tabular}

1 (2/15 cases), $7(0 / 15$ cases) and $13(3 / 15$ cases) GHQ-30s were individually compared with week 19 (7/13 cases) GHQ-30 using Fisher's exact test. There was a significant increase in GHQ-30 caseness when week 19 was compared with week $1(P=0.029)$ and week $7(P=0.0014)$. Comparison between weeks 13 and 19 approached significance $(P=0.07)$. The latter may be explained by the nurses becoming aware of the changes just before week 13 GHQ-30 and so stress levels may have increased to narrow the difference with week 19. One of the two nurses at week 1 and all three nurses at week 13 with GHQ-30 caseness were also GHQ-30 cases at week 19. There was a significant increase in CGHQ scores when week 19 was compared with week $1(P=0.032)$, week $7(P=0.008)$ and week 13 $(P=0.006)$. There was no association between GHQ-30 caseness or CGHQ score at week 19 and any of the demographic factors.

\section{Comment}

This study clearly demonstrates that major changes in service delivery are associated with stress among the nursing staff. The educational package is unlikely to have influenced the GHQ-30 scores as there was no difference between week 7 and week 13 GHQ-30 scores (the educational package was offered in that period). This is consistent with reports of burnout, poor morale and stress among nursing staff during the process of deinstitutionalisation (Lamb, 1977; Mendal, 1979). Such effects can be minimised by considering the views and needs of the staff to avoid resistance and misunderstanding (Greenblatt \& Budson, 1976; Towell \& McAusland, 1984). Managers within this provider unit were involved in regular discussions and counselling sessions with the nursing staff for these reasons. Also, the nursing staff were given an opportunity to 
move to the nursing home or consider other work in the provider unit. However, this may not be sufficient as the nurses perceived that their livelihood was threatened. Unless policymakers, purchasers and providers give serious consideration to the impact of such organisation changes on provider unit staff, not only will staff experience stress but they may leave the NHS. Recruitment of staff is already a problem and such careful consideration may help retain staff.

\section{Acknowledgements}

We thank the nursing staff for participating in our study, and Dr Tom Sensky and the anonymous referee for helpful advice.

\section{References}

BRODATY, H. \& ANDREWS, G. (1983) Brief psychotherapy in general practice; a controlled prospective intervention trial. British Journal of Psychiatry, 143, 11-19.

GoldBERG, D. (1978) Manual of the General Health Questionnaire. Windsor: National Foundation of Education Research.
- \& Williams, P. (1988) A User's Guide to the General Health Questionnaire. Windsor: National Foundation for Educational Research-Nelson.

GOODCHILD. M. E. \& DUNCAN-JONES, P. (1985) Chronicity and the General Health Questionnaire. British Joumal of Psychiatry, 146. 55-61.

GREENBLATT, M. \& BUDSON, R. (1976) A symposium: followup studies of community care. American Journal of Psychiatry, 133, 916-921.

LAMB, H. (1977) The state hospital: facility of last resort. American Journal of Psychiatry, 134, 1151-1 152.

MENDAL, W. (1979) Staff burnout: diagnosis, treatment and prevention. In New Directions for Mental Health Services: Community Support System for the Long Term Patient (ed. L. Stein). No 2. San Francisco, CA: Josey Bass.

TOWELl, D. \& MCAUSLAND, T. (1984) Managing psychiatric services in transition. Health and Social Services Journal, 25, 1-8.

*Ajit Shah, Senior Lecturer in Psychiatry of Old Age, and Tamal De. Clinical Research Fellow, Department of Psychiatry. Charing Cross and Westminster Medical School, London

Correspondence: Dr A. Shah, Ward MWl, West Middlesex University Hospital, Twickenham Road, Isleworth, Middlesex TW7 6AF

\title{
Influence of mailing strategies on response to questionnaires
}

\author{
Kate Newton, Samuel M. Stein and Clare Lucey
}

\begin{abstract}
Aims and method A prospective study was undertaken to evaluate the effect of a stamped addressed envelope, as compared to a non-stamped but addressed envelope or no envelope, on response to a mailed questionnaire. The correlation between questionnaire response and subsequent attendance at the first appointment was also studied.

Results The overall response rate was $26 \%$ of 176 familles offered first appointments at a local child psychiatry service. Families provided with a stamped addressed envelope were more likely to return their questionnaire and those families who returned the questionnaire were more likely to attend their first appointment. Clinical implications The return of patient questionnaires has significant clinical and resource implications. Only essential questionnaires should be sent out to referred families as nearly three-quarters will not be returned. The return rate can be enhanced by providing a stamped addressed envelope but, if questionnaires are not returned within 10 days, the likelihood of
\end{abstract}

return is minimal. As more than half of the families who failed to return the questionnaire also failed to attend their first appointment, questionnaires can be used as a measure of motivation and likelihood of attendance as well as a source of clinical information.

Questionnaires are routinely sent to all families prior to their first attendance at the Child and Family Consultation service in Ealing, West London. Previous studies have demonstrated an increased response rate to postal surveys if a stamped addressed envelope was included (Erdos, 1957; Veiga, 1974: Leitner et al, 1979; Choi et al, 1990). Mathai \& Markantonakis (1990), found that sending a questionnaire might ensure better attendance of a family to a child psychiatric unit.

The hypothesis tested was that the enclosure of a stamped addressed envelope would improve both the response to a preliminary questionnaire and subsequent attendance at the first appointment. 